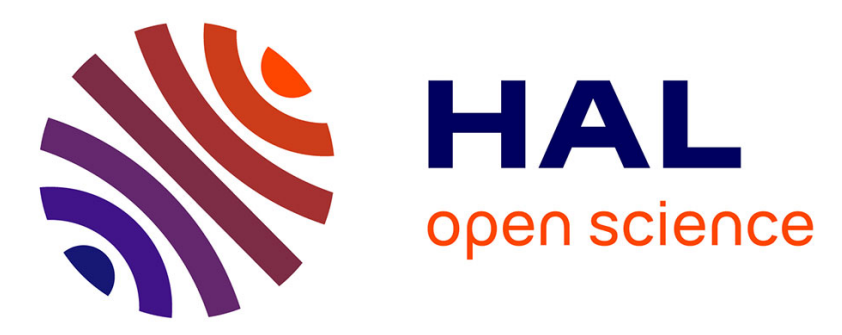

\title{
A Central Role for Polyamines in Microtubule Assembly in Cells
}

\author{
Philippe Savarin, Aurélie Barbet, Stephanie Delga, Vandana Joshi, Loic \\ Hamon, Julien Lefevre, Samir Nakib, Jean-Pascal de Bandt, Christophe \\ Moinard, Patrick A Curmi, et al.
}

\section{To cite this version:}

Philippe Savarin, Aurélie Barbet, Stephanie Delga, Vandana Joshi, Loic Hamon, et al.. A Central Role for Polyamines in Microtubule Assembly in Cells: Polyamines favor MT assembly. Biochemical Journal, 2010, 430 (1), pp.151-159. 10.1042/BJ20091811 . hal-00506521

\section{HAL Id: hal-00506521 \\ https://hal.science/hal-00506521}

Submitted on 28 Jul 2010

HAL is a multi-disciplinary open access archive for the deposit and dissemination of scientific research documents, whether they are published or not. The documents may come from teaching and research institutions in France or abroad, or from public or private research centers.
L'archive ouverte pluridisciplinaire HAL, est destinée au dépôt et à la diffusion de documents scientifiques de niveau recherche, publiés ou non, émanant des établissements d'enseignement et de recherche français ou étrangers, des laboratoires publics ou privés. 


\section{A Central Role for Polyamines in Microtubules Assembly in Cells}

Philippe Savarin ${ }^{1}$, Aurélie Barbet ${ }^{1}$, Stéphanie Delga ${ }^{1}$, Vandana Joshi ${ }^{1}$, Loïc Hamon ${ }^{1}$, Julien Lefevre $^{1}$, Samir Nakib ${ }^{3}$, Jean-Pascal De Bandt ${ }^{2,3}$, Christophe Moinard ${ }^{2}$, Patrick A. Curmi ${ }^{1, *}$ and David Pastré ${ }^{1, *}$

1 - Institut National de la Santé et de la Recherche Médicale (INSERM), UMR829; Université Evry-Val d'Essonne; Laboratoire Structure-Activité des Biomolécules Normales et Pathologiques, Evry 91025, France.

2 - Laboratoire de biologie de la nutrition, EA2498, département de biologie expérimentale, métabolique et clinique, faculté de pharmacie, université Paris-Descartes, Paris, France

3 - Service de biochimie, Hôtel-Dieu, AP-HP, 1, place du Parvis-Notre-Dame, 75181 Paris cedex 04, France

* Corresponding author, email: david.pastre@univ-evry.fr Tel 33169470179 Fax 33169 4702 19,pcurmi@univ-evry.fr

Keywords: MTs, Polyamines, Cytoskeleton Dynamics, MAPs, EB1, Connexin 43

Short title: Polyamines favor MT assembly 


\section{SYNOPSIS}

Due to preferential electrostatic adsorption of multivalent cations on highly anionic surfaces, natural multivalent polyamines and especially tetravalent spermine can be considered as potential regulators of the complex dynamical properties of anionic microtubules (MTs). Indeed the C-terminal tails of tubulin display many negative residues in a raw which should enable the formation of a correlated liquid-like phase of multivalent counterions on its surface. Although it is known that polyamine counterions promote MT assembly in vitro, little is known about the relevance of this interaction in vivo. We explore here the relationship between polyamine levels and MT assembly in HeLa and epithelial NRK cells using DFMO, an irreversible inhibitor of ornithine decarboxylase, and APCHA, a spermine synthase inhibitor. Under conditions of intracellular polyamine depletion, the MT network is clearly disrupted and the MT mass decreases. Addition of spermine to polyamine-depleted cells reverses this phenotype and rapidly promotes the extensions of the MT network. Finally we show that polyamine levels modulate the coating of MTs with MAP4, a MT-stabilizing protein, and the spatial distribution of EB1, a MT plus-end binding protein. In addition, polyamines favor the formation of gap junctions in NRK cells, a process which requires MT extensions at the cell periphery. This work provides basis for a better understanding of the role played by polyamines in MT assembly and establishes polyamine metabolism as a potential cellular target for modulating MT functions. 


\section{INTRODUCTION}

Polyamines are polycationic alkylamines that are present at millimolar concentrations in all eukaryotic organisms [1,2]. Tetravalent spermine, trivalent spermidine and their diamine precursor putrescine are key modulators of cell growth and also of cancer cell invasiveness [3]. Polyamine metabolism has thus long been considered as a potential target for cancer treatment [4]. After some disappointing initial clinical trials, drugs that target polyamine metabolism like DFMO ( $\alpha$-DiFluoroMethyl-Ornithine) are now the object of renewed interest [5-11], especially with the recent development of polyamine-deficient diets to restrain exogenous polyamine uptake [12]. Polyamines were first thought to be mostly involved in RNA and DNA processing $[13,14]$. The highly acidic surfaces of nucleic acids attract polyamines via electrostatic forces and polyamines, as counterions, could thus regulate gene expression and protein synthesis [13, 14]. Alternatively, polyamines may also bind other anionic macromolecules [15]. Among these anions, cytoskeleton proteins like actin and tubulin, the building block of microtubules (MTs), should be considered as potential candidates for polyamine binding [16]. Most studies on cytoskeleton/polyamine interactions have focused on actin filaments and showed that the depletion of intracellular polyamine pools induces significant modifications in actin cytoskeleton architecture and disappearance of actin stress fibers [17, 18]. However, even if polyamines can directly promote actin polymerization in vitro, recent studies indicate that the disruption of actin filaments after polyamine depletion might rather be due to the inactivation of proteins of the Rho family such as Rac1, which regulates the organization of the actin cytoskeleton [19, 20].

Although the negative charge of tubulin (20-30 e- per tubulin heterodimer, [21]) is comparable to that of actin ( 11-14 e- per subunit of an actin filament, [22, 23]), tubulin may be an even better candidate for polyamine binding than actin because most of its charge is concentrated in the C-terminal tails. Indeed, due to the presence of numerous stretches of negative residues $\left(\sim 10-15 \mathrm{e}^{-},[21,24,25]\right)$, the C-terminal tail of tubulins, pointing outward the MT cylinder, has a local negative charge density at least comparable to that of DNA or RNA [16]. Surprisingly, little is known about the influence of polyamines on the MT network in cells. After a pioneer report in 1981 showing the disappearance of MTs in polyamineauxotrophic CHO cells deprived of polyamines [17], only a limited number of experimental studies has been conducted to further address this issue. Two decades later, a report described the regulation by polyamines of MT formation during gastric mucosal healing [26]. More recently, MT- and polyamine-targeting drugs have been proposed as an interesting combination therapy to induce apoptosis of breast cancer cells [27]. Taking into account the therapeutic potentialities opened by this MT/polyamine relationship, notably in terms of cancer treatment, the influence of polyamines on the MT network deserves to be explored. The aim of the present work is to study in cultured cells the impact of polyamine levels on MT assembly and on the spatial distribution of MTs. We show that multivalent polyamines promote MT elongation at the cell periphery and influence MT regrowth after cold depolymerization. Polyamines also modulate the mass of polymerized tubulin and modify the coating of MTs with Associated Proteins (MAPs). In addition to its effect on MT network and as a consequence of this, our results indicate that polyamines may regulate the formation of gap junctions at the interface between epithelial cells. 


\section{MATERIALS AND METHODS}

\section{Tubulin Preparation}

Tubulin was purified from sheep brain crude extracts as described previously [28].

\section{MT Assembly}

$30 \mu \mathrm{M}$ tubulin were pre-incubated on ice for $5 \mathrm{~min}$ in polymerization buffer $(50 \mathrm{mM}$ MES$\mathrm{KOH}$ pH 6.8, $50 \mathrm{mM} \mathrm{KCl,} \mathrm{20 \%} \mathrm{glycerol,} 1 \mathrm{mM}$ EGTA, $4 \mathrm{mM} \mathrm{MgCl}_{2}, 1 \mathrm{mM}$ GTP) in the presence or absence of polyamines. Tubulin polymerization was then initiated by shifting temperature to $37^{\circ} \mathrm{C}$ in an Ultrospec 3000 spectrophotometer (GE Healthcare, Fairfield, USA) equipped with a temperature controller. The kinetics of MT assembly was monitored by measuring absorbance at $350 \mathrm{~nm}$.

The effects of polyamines on tubulin assembly were also analyzed by sedimentation assay. In this case, MTs were pelleted at $25,000 \times \mathrm{g}$ for $30 \mathrm{~min}$ at $37{ }^{\circ} \mathrm{C}$ and resuspended in $25 \mathrm{mM}$ MES-KOH at $4^{\circ} \mathrm{C}$ in the initial sample volume. Equal volumes of supernatant and resuspended pellet were analyzed and compared on a 12\% SDS-PAGE.

\section{Atomic Force Microscopy (AFM)}

Ten microliters of sample were deposited on freshly cleaved mica and dried for AFM imaging as previously described [29]. All AFM experiments were performed in intermittent mode with a multimode AFM instrument (Digital Instruments, Veeco, Santa Barbara, CA) operating with a Nanoscope IIIa controller (Digital Instruments). We used AC160TS silicon cantilevers (Olympus, Hamburg, Germany) with resonance frequencies of around $300 \mathrm{kHz}$. The applied force was minimized as much as possible. Images were collected at a scan frequency of $1.5 \mathrm{~Hz}$ and a resolution of $512 \times 512$ pixels.

\section{Cell culture}

HeLa and NRK 52-E cells (ATCC, USA) were maintained in Dulbecco's modified Eagle's medium (DMEM) supplemented with 5\% fetal calf serum (FCS), $2 \mathrm{mM}$ L-glutamine and 1\% antibiotics (penicillin and streptomycin) in a humidified $5 \% \mathrm{CO}_{2}$ atmosphere at $37^{\circ} \mathrm{C}$. To evaluate the effect of polyamines, cells were plated on plastic dishes or flasks in the above mentioned medium except FCS was dialyzed to eliminate exogenous polyamines. Control cells were grown in this medium for 72 h. $1 \mathrm{mM}$ DFMO (Sigma-Aldrich) and (or) $100 \mu \mathrm{M} \mathrm{N}$ (3-AminoPropyl) CycloHexylAmine (APCHA, Alexis, Biochemicals, NY, USA) were used in order to deplete polyamines for 3 days. To inhibit serum polyamine oxidase, aminoguanidine $(1 \mathrm{mM})$ was added to the growth medium when cells were supplemented with polyamines.

\section{Immunofluorescence}

HeLa or NRK cells grown on plastic dishes were washed with PBS and fixed with methanol for $10 \mathrm{~min}$ at $-20^{\circ} \mathrm{C}$. After fixation, cells were then washed and incubated for 1 hour with a mouse monoclonal anti-tubulin antibody (1:2000, E7 monoclonal antibody), a mouse antiMAP4 monoclonal antibody (1:1000 dilution, Clontech), a rabbit polyclonal anti-Cx43 antibody (1:200, ab11370, ABcam) or a monoclonal mouse anti-EB1 (1:500, BD Biosciences) in blocking solution (50 mM Tris- $\mathrm{HCl}, \mathrm{pH} 7.5,150 \mathrm{mM} \mathrm{NaCl}, 0.1 \%$ Triton X-100, 2\% BSA). Cells were washed extensively in PBS and incubated for $1 \mathrm{~h}$ with fluorochrome-coupled secondary antibodies (AlexaFluor488, Invitrogen, California, USA) in blocking solution. After final washes with PBS, samples were prepared for fluorescence microscopy analysis. 


\section{Immunoblotting}

Cells were washed once with PBS, and then lysed in $50 \mathrm{mM}$ Tris- $\mathrm{HCl}, \mathrm{pH} 7.5,150 \mathrm{mM} \mathrm{NaCl}$, $1 \%$ Nonidet P40, $1 \mathrm{mM}$ EDTA and protease inhibitor cocktail (Roche, Basel, Switzerland). Lysates were centrifuged at $14,000 \times \mathrm{g}$ for $15 \mathrm{~min}$ at $4^{\circ} \mathrm{C}$, and supernatants were collected. Proteins were separated on a 12\% SDS-PAGE and transferred to a PVDF membrane (Invitrogen, California, USA). The membranes were blocked in 5\% non-fat dry milk/PBS for $30 \mathrm{~min}$ at room temperature, and incubated for $1 \mathrm{~h}$ at room temperature with primary antibodies (anti-tubulin, anti-MAP4 and anti-EB-1). Bound antibodies were detected and quantified using anti-rabbit-IRDye 800 or anti-mouse-IRDye 680 secondary antibodies (Odyssey, 1:2 000 dilution) with an Odyssey imaging system (LI-COR Biosciences, Lincoln, USA).

\section{Preparation of free and polymerized tubulin Fractions}

We used the method described by Gundersen et al. with minor modifications [30]. Cultured HeLa cells were rinsed with $85 \mathrm{mM}$ Pipes, pH 6.9, $1 \mathrm{mM}$ EGTA, $1 \mathrm{mM} \mathrm{MgCl}_{2}, 2 \mathrm{M}$ glycerol, and protease inhibitors and then extracted with the same buffer containing $0.4 \%$ Triton $\mathrm{X}$ 100. After $3 \mathrm{~min}$, the soluble fraction (free tubulin) was gently transferred to a graduated tube, mixed with 1/4 volume of 5x SDS-PAGE buffer (10\% SDS, $325 \mathrm{mM}$ Tris-HCl, pH 6.8, 30\% glycerol and $1 \mathrm{mM}$ phenylmethylsulfonyl fluoride) and boiled for $5 \mathrm{~min}$. The polymerized tubulin fraction, corresponding to MTs remaining in the cells, was then solubilized in SDS buffer with a volume equivalent to that of the soluble fraction and boiled for $5 \mathrm{~min}$. An identical volume of free and polymerized tubulin fractions was loaded on the SDS-PAGE gel for each condition and the tubulin content was determined by immunoblotting with antitubulin antibody as described above.

\section{Intracellular polyamine quantification}

Polyamines were measured according to a modification of the method of Loukou and Zoutou with modifications [31] by dansyl derivatization and ion-paired reverse phase high-pressure liquid chromatography using fluorometric detection. In brief, samples $(3 \mathrm{mg} / \mathrm{mL}$ of protein from HeLa cell extracts) were centrifuged (at 3,000 $\times$ g for $5 \mathrm{~min}$ ). $25 \mu \mathrm{L}$ of supernatants were homogenized with borate buffer $(0.4 \mathrm{M}, \mathrm{pH}=9,2 \mathrm{~mL})$ and incubated for $90 \mathrm{~min}$ at $100^{\circ} \mathrm{C}$ in the dark with $0.5 \mathrm{~mL}$ of dansyl chloride $(5 \mathrm{mg} / \mathrm{mL}$ in acetone). Dansyl derivatives were purified by solid phase extraction (Bond Elut Certify ${ }^{\circledR}$ cartridge). The organic phase was collected, evaporated and the dansyl derivatives were resuspended in $1 \mathrm{~mL}$ of the initial mobile phase. The separation of dansyl-putrescine, dansyl-spermidine, and dansyl-spermine was performed on $\mathrm{C} 18$ luna $^{\circledR}$ column (length $25 \mathrm{~cm}$, particle diameter $5 \mu \mathrm{m}$ ) with acetonitrile/water gradient on a Dionex ${ }^{\circledR}$ system for fluorometric detection. Polyamine concentrations were estimated by the internal standard method (standard: hexane diamine). Results are expressed as nanomoles per milligram of protein. The reported value was averaged over three different samples for each condition and the error represents the standard deviation from this value.

\section{RESULTS AND DISCUSSION}

\section{Polyamines favor MTs assembly in vitro}

To evaluate the effect of polyamines on MT assembly, we performed a series of in vitro experiments. We first determined the kinetics of tubulin polymerization (fig. 1A) and observed that the maximum slope of the MT assembly curve, which is a good indicator of the MT nucleation efficiency, increased significantly in the presence of tetravalent spermine 
(slope $\sim 0.8$ a.u./min for spermine compared to 0.2 a.u./min for control) and to a lesser extent with trivalent spermidine $(0.28$ a.u./min), whereas divalent putrescine was ineffective in promoting MT assembly (0.16 a.u./min). These results indicate that the beneficial effect of polyamines on MT assembly depends on polyamine valence. This was expected due to the power law dependence on counterion charge of the electrostatic binding energy to tubulin [16].

In addition, we noted that spermine and, to a lesser extent, spermidine lower the critical concentration, i.e. the concentration of free tubulin in equilibrium with MTs, and thus, as a reciprocal consequence, increases MT mass (fig. 1B). Another indicator of the increased polymer mass is the higher plateau value in the presence of spermine $(\sim 1$ a.u. $)$ or spermidine $(\sim 0.75$ a.u.) than in control ( 0.65 a.u.) (fig. 1A). High resolution imaging of MTs was also performed using Atomic Force Microcopy (AFM) and showed that, in the presence of spermine, normal MTs and not aberrant structures were formed under our experimental conditions (fig. 1C).

Interestingly, as the tubulin polymerization assays were performed at ionic strength comparable to that of living cells (50 mM MES-KOH, $50 \mathrm{mM} \mathrm{KCl,} 4 \mathrm{mM} \mathrm{MgCl} 2$ ), we also noted that the screening by monovalent salts of electrostatic interaction was not sufficient to inhibit the positive effect of multivalent polyamines on MT assembly [16]. These results prompted us to investigate the potential effect of polyamines on living cells.

\section{Polyamine depletion in HeLa cells affects the architecture of the MT network.}

We first evaluated whether polyamines were involved in the construction of the MT network of living cells by targeting polyamine metabolism of HeLa cells. For this purpose, experiments were performed with two inhibitors of polyamine metabolism alone or in combination: DFMO, an irreversible inhibitor of Ornithine DeCarboxylase (ODC), at low concentration to deplete putrescine only without affecting the levels of both spermidine or spermine, APCHA, an inhibitor of spermine synthase, to obtain a significant spermine depletion [32-34]. To evaluate whether these drugs actually modulate the intracellular concentrations of polyamines, the levels of polyamines in HeLa cells after drug treatments were measured by high-pressure liquid chromatography after dansyl derivatization (see table 1). The results revealed that a 72 hour-exposure to $1 \mathrm{mM}$ DFMO alone depleted intracellular putrescine whereas the spermidine and spermine levels only slightly decreased. A similar treatment with $100 \mu \mathrm{M}$ APCHA significantly decreased the spermine level but a compensatory mechanism took place which resulted in an increased spermidine level [32]. However, in the simultaneous presence of DFMO and APCHA, both the spermine and spermidine levels decreased. Interestingly, putrescine supplementation during cell incubation with DFMO and APCHA increased drastically the spermidine level but failed to change spermine level, which indicates the efficiency of APCHA to block spermine synthesis.

We then explored the effect of these drugs on the MT network of HeLa cells by immunostaining (fig. 2). The MT network in the presence of $1 \mathrm{mM}$ DFMO for 3 days appeared similar to that of control cells (fig. 2A). This result clearly indicates that putrescine is not mandatory to maintain the MT architecture (fig. 1, table 1). When cells were treated with APCHA alone for 3 days the MT network was also apparently unaffected (fig. S1). In this case, the increase in spermidine in reaction to spermine depletion may counteract the effect of spermine depletion on MT assembly. To observe a clear impact of polyaminetargeting drugs on MTs in cells, a decrease in both spermidine and spermine levels might thus be necessary, which was obtained by using DFMO and APCHA in combination for 3 days (table 1). This hypothesis is supported by our results as, after treatment with both DFMO and APCHA, a partial disruption of the MT network occurred with only few extensions of the MT network away from the centrosome and less MTs oriented normal to the cell edge (fig. 2A). 
When, in order to bypass the induced deficiencies of polyamine metabolism, spermine was supplemented at the beginning of the treatment with DFMO and APCHA, cells had a normal MT network even at their edges (fig. 2B).

\section{Polyamine supplementation triggers the regrowth of MTs in polyamine-depleted cells}

To further evaluate the implication of polyamines in the regulation of MT architecture in cells, we studied the effect of polyamine supplementation on the MT network of cells previously treated with DFMO and APCHA for 3 days. For this purpose, spermine was added to the culture medium containing DFMO and APCHA. Within $1 \mathrm{~h}$, the effect of spermine on the MT network of polyamine-depleted cells was clearly observed (fig. 3A). In particular, MTs no longer looked disrupted and long MTs perpendicular to the plane of the cell membrane reappeared. This effect is even more pronounced for longer incubation time in the presence of spermine $(3 \mathrm{~h})$. However, the addition of putrescine for $3 \mathrm{~h}$ to DFMO and APCHA-treated cells led only to a partial recovery of the MT network (fig.3A) indicating that, under such condition, putrescine or more importantly newly synthesized spermidine (see table 1) cannot fully compensate the negative effect of missing spermine on MT assembly. These results indicate that spermine and probably spermidine help to incorporate free tubulin to MT plus-ends and thus promote extension of the MT network toward the cell periphery. To explore this idea, we analyzed the spatial distribution of endogenous EB1, a MT plus-end binding protein (fig. 3B). It has been reported that taxol treatment, which totally suppresses MT dynamics, leads to the dissociation of EB1 from MT ends [35]. More generally, when MTs are stable, EB1 labeling exhibits a puncta-like distribution at the MT ends. On the other hand, dynamical MT ends labeled with EB1 show a comet-like appearance due to a rapid MT elongation during the residency time of EB1 on MTs [36, 37]. After DFMO and APCHA treatment, EB1 labeling led to the appearance of puncta at MT ends whereas, after the addition of spermine, we observed a clear comet-like appearance, thus revealing a higher rate of MT elongation under such condition. The spermine-dependent extensions of the MT network at the cell periphery could be explained by a model that we recently developed which states that multivalent polyamines could facilitate the delivery of tubulin dimers to the MTs ends [16]. The point is that polyamines may allow incoming tubulin to slide along MTs via electrostatic attraction, thus increasing the chances of free tubulin to find MT ends. The beneficial effect of this mechanism for the extensions of the MT network is especially relevant at the cell periphery where the flow of free tubulin arriving at the MT plus-ends may be too scarce to support MT elongation. In addition to promoting MT elongation, it has been shown that spermine activates GTPases of the Rho family such as Rac1 which in turn orchestrates an increase in F-actin in the cell interior while decreasing it in the cell cortex [18]. A lighter actin filament network in the cell cortex should then favor the passage of MTs and thus also facilitate MTs extensions at the cell periphery. However, another pathway may also be advanced. As MT growth is known to activate Rac1 [38], polyamine-mediated MT extensions can thus indirectly orchestrate the redeployment of actin filaments [18].

\section{Polyamines modulate the MT network of epithelial NRK cells and interactions between cells}

As the architecture of the cytoskeleton network at the cell periphery is crucial for cell-cell interaction [39] and cell migration [40], the action of polyamines on the MT network then may provide an alternative explanation for previous reports on the promotion by polyamines of cell migration [41] and cell-cell junctions [42]. To test this hypothesis, we used Normal Rat Kidney epithelial cells (NRK-52E), derived from proximal tubule. Our data show that the MT network of NRK cells behaved similarly to HeLa cells upon polyamine depletion, with restricted MT extensions leading to an appearance of compacted cell clusters (fig. 4A). 
Supplementation of spermine $(500 \mu \mathrm{M})$ led to rapid rearrangements of the MT network with MT extensions at the cell edge. We can thus reasonably assume that the role played by polyamines on MTs is not restricted to HeLa or NRK cells but is most probably shared by many eukaryotic cells.

Since dynamic MT extensions at the cell periphery are necessary for the formation of gap junction, polyamines levels may promote their formation by promoting the extension of MT toward the cell membrane. To address this issue, we investigated the formation of connexin 43 (Cx43) gap junctions, which are abundant in NRK cells. The point is that $\mathrm{Cx} 43$ displays a tubulin binding domain [43] and there is a large body of evidence that dynamic MTs directly target $\mathrm{Cx} 43$ at the cell membrane to participate in the formation of large gap junction plaques [44]. After polyamine depletion with DFMO for 3 days, we noted that, compared to control, Cx43 spatial distribution appeared more diffused at the interface between NRK cells with less Cx43 plaques (fig. 4B). When cells were treated with DFMO and APCHA, this effect was more pronounced and we rarely observed the formation of large gap junction plaques in agreement with the partial disruption of the MT network under such conditions. These data indicate that polyamines may influence the subcellular localization of $\mathrm{Cx} 43$ via a MTdependent mechanism, which may in turn possibly affect $\mathrm{Cx} 43$ expression $[45,46]$.

\section{Polyamines modulate the mass of MTs and the coating of MTs with MAP4}

To go beyond the observation of MT morphological changes, the measurement of the intracellular concentrations of free and polymerized tubulin is an interesting indicator [47]. Changes in free tubulin pool coexisting with MTs can reveal subtle but important modifications in the thermodynamic equilibrium which rules the assembly of highly dynamic MTs. We then quantified the effect of polyamines on the free and polymerized tubulin pools of living cells by western blotting [30]. The results of this experiment (fig. 5) clearly indicate that the concentration of free tubulin in DFMO-treated cells increased at the expense of the polymerized tubulin pool. Interestingly, the relative concentration of free tubulin further increased when APCHA was used in combination with DFMO whereas supplementation of spermine or putrescine during drug exposure allowed the partial recovery of the MT mass. We also noted that putrescine was less potent than spermine in recovering the polymer mass in DFMO and APCHA-treated cells, most probably because the spermine concentration remained low after its addition, even though there was a net increase in the spermidine level (table 1).

The significant change in the percentage of polymerized tubulin upon polyamine depletion clearly indicates that polyamines and especially spermine play a major role in MT dynamics. As the MT network is also under the control of MAPs, we then naturally wonder whether an interplay between polyamines and MAPs may orchestrate MT assembly and dynamics. To address this issue, we chose MAP4, the most abundant MT-associated protein in HeLa cells, which binds along the MT wall to promote MT stabilization [48, 49]. Moreover MAP4 interacts with the C-terminal tail of tubulin [50] on which polyamine counterions are potentially bound. As previously reported [48], the coating of MTs by MAP4 in control cells is not continuous (fig. 6), which explains why MTs appeared diffuse after anti-MAP4 immunostaining. In DFMO-treated cells, the MAP4 labeling resulted in a more contrasted MT network, which indicates that the surface density of MAP4 on MT wall was higher than in control cells. When APCHA was used in combination with DFMO, the coating of MTs with MAP4 was also denser but we also remarked that the concentration of MAP4 around the centrosomal region was markedly increased compared to control cells. Indeed, remaining MTs were mostly located around the centrosome area where nucleation-facilitating agents are present. The addition of spermine during DFMO or DFMO and APCHA treatments reversed the MT network appearance to the diffuse pattern typical of untreated HeLa cells. 
The increased MAP4 decoration of MTs after polyamine depletion could simply result from a lower mass of MTs under such conditions. Indeed, one of the major characteristic of MAP4 is that it binds MTs with a high affinity while its interaction with free tubulin is weak. When, after polyamine depletion, MT mass decreases (fig. 5), the density of MAP4 along MTs should then correspondingly increase. However polyamine depletion may also influence MAP4 intracellular concentration. In order to probe this idea, we showed using a western blot assay that the intracellular concentration of MAP4 was not significantly altered after 3 days of DFMO or DFMO and APCHA treatments (fig. S3), which indicates that the higher density of MAP4 along MTs was not due to MAP overexpression.

In light of these results, a role of polyamines in MAPs/MT interactions emerges as an interesting novel player. At high polyamine concentrations, a lower density of MAPs on MTs may result in more dynamical MTs whereas, at lower polyamine concentrations, a denser MAPs coating on MTs may lead to their stabilization.

\section{Polyamines inhibit rapid MT regrowth after cold-induced depolymerization}

HeLa cells were placed on ice for $1 \mathrm{~h}$ to allow total MT depolymerization. MT regrowth was then observed at various times after returning to $37{ }^{\circ} \mathrm{C}$ (fig. 7). In control cells, MT regrowth was relatively slow and only tiny MT asters were observed 2 min after rewarming, as previously reported [30, 51-53]. Surprisingly, in polyamine-depleted cells, MT regrowth from the centrosome was significantly quicker than in control cells. After only 2 min at $37^{\circ} \mathrm{C}$, DFMO-treated cells displayed many long MTs extending from the centrosomal area which already formed an aster. MT asters were also developed in cells treated with APCHA and DFMO. Similar results were obtained after 10 min rewarming at $26{ }^{\circ} \mathrm{C}$ to slow down MT regrowth (fig. S4). In contrast with our results obtained in vitro (fig. 1), the presence of polyamines in cells then inhibits MT regrowth from the centrosome. However we noticed the presence of acentrosomal short MTs in the cytoplasm of control cells that were absent in the cytoplasm of polyamine depleted cells. Such acentrosomal nucleation may be promoted by polyamines and may then slow down the formation of normal MT aster from the centrosome (fig. S5). The higher concentration of MAP4 in the centrosomal region in polyamine-depleted cells than in control cells may also account for their higher rate of MT aster regrowth (fig. 6). In line with this hypothesis, faster MT regrowth after cold depolymerization was reported in the absence of Mast in Drosophila S2 culture cells [54]. Mast is the Drosophila homologue of CLASP, a member of the MTs plus-end tracking proteins (+TIPs), which is implicated in the nucleation of acentrosomal MTs [55]. Another hypothesis that deserves further investigations is that cells may overproduce nucleation factor or MAPs to compensate for the absence of polyamines or relocalize them in the centrosomal region, as observed for MAP4 after DFMO and APCHA treatment (fig. 6).

In summary, our results indicate that variations in polyamine levels significantly modulate both microtubule mass and dynamics. As polyamine metabolism is a known target to treat cancer, a better understanding of the mechanism by which polyamines limit cell growth may provide basis for future development of original strategies for example by combining microtubule- and polyamine-targeting drugs. Another point is to explore whether polyamines, via their action on cytoskeleton, modulate cell-cell interactions, especially in epithelia. 


\section{FIGURE CAPTIONS}

Figure 1: Polyamines promote MT assembly and increase MT mass in vitro.

(A) MT assembly was assessed by turbidimetry. $30 \mu \mathrm{M}$ tubulin were polymerized in the presence or absence of $300 \mu \mathrm{M}$ putrescine, spermidine or spermine (at $37^{\circ} \mathrm{C}$ in $50 \mathrm{mM} \mathrm{MES}$ $\mathrm{KOH} \mathrm{pH}$ 6.8, $50 \mathrm{mM} \mathrm{KCl,} 1 \mathrm{mM}$ EGTA, $1 \mathrm{mM}$ GTP, $4 \mathrm{mM} \mathrm{MgCl}_{2}, 20 \%$ glycerol. In the presence of spermidine and more significantly spermine, the maximal slope of assembly is steeper and the plateau value is higher than in control or in the presence of putrescine, which indicates the beneficial effect of multivalent polyamines on MT assembly.

(B) SDS/PAGE analyses of MT assembly in the absence or presence of polyamines and quantification. MTs (pellet, P) and free tubulin (supernatant, S). In the presence of spermidine (Spd) and, more significantly, spermine (Spm), the mass of polymerized tubulin increases at the expense of free tubulin whereas an increase in MT mass in the presence of putrescine (Put) is barely detectable, if any, in agreement with the plateau values observed in (A). The error bars represent standard deviation over 3 different samples.

(C) AFM images of MTs assembled in the absence or presence of $300 \mu \mathrm{M}$ spermine in polymerization buffer. In the presence of spermine, MTs display a normal shape with a trend to form bundles (arrow), which is the result of the binding of cationic spermine on MTs (attraction mediated by multivalent counterions).

Figure 2: Polyamine depletion affects MT architecture.

(A) HeLa cells labeled with anti- $\alpha$-tubulin after indicated treatments for 3 days. Compared to controls and DFMO-treated cells, cells treated with DFMO $(1 \mathrm{mM})$ and APCHA $(100 \mu \mathrm{M})$ in combination exhibit a disrupted MT network with fewer extensions away from the perinuclear region. Addition of spermine $(100 \mu \mathrm{M})$ during the treatment allows the maintenance of an undisrupted MT network.

(B) Higher magnification of MTs showing the tendency of MTs to adopt a direction parallel to cell borders after DFMO plus APCHA treatment. The population of MTs extending perpendicularly to cell edges can be recovered when spermine $(100 \mu \mathrm{M})$ is added during the treatments with DFMO plus APCHA. The contrast has been reversed to better visualize MTs.

Figure 3: Addition of spermine after DFMO and APCHA treatment allows the rapid extension of the MT network.

(A) HeLa cells labeled with anti- $\alpha$-tubulin after 3 days treatment with a combination of DFMO and APCHA exhibit a disrupted MT network. After $1 \mathrm{~h}$ of spermine supplementation $(500 \mu \mathrm{M})$, the MT network is already in partial extension toward the cell periphery and its extension is more drastic after $3 \mathrm{~h}$. The extension of the MT network occurred to a lesser extent when putrescine is added instead of spermine.

(B) Polyamine depletion affects EB1 distribution at MT ends. HeLa cells were treated with DFMO and APCHA in combination and labeled with anti-EB1. Under such conditions, cells exhibit a low density of EB1 puncta at MT ends whereas in control and more significantly after the addition of $500 \mu \mathrm{M}$ spermine, the endogenous EB1 staining displays a comet like appearance, in agreement with a higher rate of MT growth and more dynamical MTs (the expression of EB-1 is not modified by DFMO and APCHA treatment and spermine addition, fig. S2)

Figure 4: Polyamines favor the extension of the MT network and regulate the formation of gap junctions in epithelial cells.

(A) NRK cells labeled with anti- $\alpha$-tubulin after 3 days treatment with DFMO (1 $\mathrm{mM})$ and APCHA $(100 \mu \mathrm{M})$ in combination exhibit a disrupted MT network. After $3 \mathrm{~h}$ of spermine 
supplementation $(500 \mu \mathrm{M})$, the MT network already displays partial extension toward the cell periphery.

(B) Dual labeling of NRK cells with anti-tubulin and anti-Cx43. Polyamines depletion by DFMO treatment for 3 days leads to a more homogenous distribution of $\mathrm{Cx} 43$ at the interface between cells and to fewer gap junction plaques than in control cells. Treatment of NRK cells with DFMO and APCHA significantly inhibits the formation of gap junctions.

Figure 5: Polyamine depletion decreases the mass of polymerized tubulin in HeLa cells.

(A) Western blot analyses of HeLa cell fractions containing free or polymerized tubulin (see Materials and Methods) after treatments with DFMO (1 mM) or DFMO and APCHA (100 $\mu \mathrm{M})$ for 3 days and in the absence or presence of exogenous polyamines $(0.5 \mathrm{mM}$ putrescine and $0.1 \mathrm{mM}$ spermine).

(B) Ratio of intracellular polymerized to total tubulin extracted from (A). DFMO treatment results in a net decrease in MT mass and a corresponding increase in free tubulin while the total amount of tubulin (free and polymerized tubulin) is not significantly changed compared to control cells. When APCHA is used in combination with DMFO, MT depolymerization is more dramatically decreased than with DFMO alone. Addition of spermine $(100 \mu \mathrm{M})$ and putrescine $(0.5 \mathrm{mM})$ leads to a partial recovery of the MT mass ratio, with a more pronounced effect for spermine. Error bars represent the standard deviation from the mean value over three different samples.

Figure 6: Polyamines reduce the surface density of MAP4 along MTs in HeLa cells.

MAP4 labeling in control HeLa cells or after intracellular polyamine depletion. MAP4 clearly co-localizes with MTs in control cells but MTs appear diffuse due to a low surface density of MAP4 along MTs. In polyamine-depleted cells, MTs appear with a higher contrast than in control cells. In addition, when cells are treated with DFMO plus APCHA, the centrosomal region appears brighter than in control cells, thus indicating a higher concentration of MAP4 in this region (see arrow).

Figure 7: Polyamine depletion accelerates MT regrowth from centrosome after cold depolymerization

After cold depolymerization, MTs of HeLa cells were allowed to regrowth at $37^{\circ} \mathrm{C}$. After 2 min at $37^{\circ} \mathrm{C}$, both treatments, DFMO alone or DFMO and APCHA, result in rapid regrowth of the MT aster from the centrosome whereas only a tiny aster was observed in control cells or when spermine $(100 \mu \mathrm{M})$ was added to counteract polyamine depletion. See also fig. S4 and S5 in supplementary files.

\section{TABLE 1}

Table 1: Intracellular concentrations of polyamines in control HeLa cells or in HeLa cells exposed to drugs that target polyamine metabolism. (see Materials and Methods for details). 


\section{REFERENCES}

1 Heby, O., Sarna, G. P., Marton, L. J., Omine, M., Perry, S. and Russell, D. H. (1973) Polyamine content of AKR leukemic cells in relation to the cell cycle. Cancer Res. 33, 2959-2964

2 Pegg, A. E. (2009) Mammalian polyamine metabolism and function. IUBMB Life. 61, 880-894

3 Wallace, H. M. (2007) Targeting polyamine metabolism: a viable therapeutic/preventative solution for cancer? Expert. Opin. Pharmacother. 8, 21092116

4 Thomas, T. and Thomas, T. J. (2003) Polyamine metabolism and cancer. J. Cell. Mol. Med. 7, 113-126

5 Gerner, E. W. and Meyskens, F. L., Jr. (2009) Combination chemoprevention for colon cancer targeting polyamine synthesis and inflammation. Clin. Cancer Res. 15, 758-761

6 Chen, Y., Weeks, R. S., Burns, M. R., Boorman, D. W., Klein-Szanto, A. and O'Brien, T. G. (2006) Combination therapy with 2-difluoromethylornithine and a polyamine transport inhibitor against murine squamous cell carcinoma. Int. J. Cancer. 118, 23442349

7 Casero, R. A., Jr. and Marton, L. J. (2007) Targeting polyamine metabolism and function in cancer and other hyperproliferative diseases. Nat. Rev. Drug. Discov. 6, 373-390

8 Basuroy, U. K. and Gerner, E. W. (2006) Emerging concepts in targeting the polyamine metabolic pathway in epithelial cancer chemoprevention and chemotherapy. J. Biochem. 139, 27-33

9 Moinard, C., Cynober, L. and de Bandt, J. P. (2005) Polyamines: metabolism and implications in human diseases. Clin. Nutr. 24, 184-197

10 Seiler, N. (2005) Pharmacological aspects of cytotoxic polyamine analogs and derivatives for cancer therapy. Pharmacol. Ther. 107, 99-119

11 Koomoa, D. L., Borsics, T., Feith, D. J., Coleman, C. C., Wallick, C. J., Gamper, I., Pegg, A. E. and Bachmann, A. S. (2009) Inhibition of S-adenosylmethionine decarboxylase by inhibitor SAM486A connects polyamine metabolism with p53Mdm2-Akt/protein kinase B regulation and apoptosis in neuroblastoma. Mol. Cancer. Ther. 8, 2067-2075

12 Linsalata, M. and Russo, F. (2008) Nutritional factors and polyamine metabolism in colorectal cancer. Nutrition. 24, 382-389

13 Thomas, T. and Thomas, T. J. (2001) Polyamines in cell growth and cell death: molecular mechanisms and therapeutic applications. Cell. Mol. Life. Sci. 58, 244-258

14 Watanabe, S., Kusama-Eguchi, K., Kobayashi, H. and Igarashi, K. (1991) Estimation of polyamine binding to macromolecules and ATP in bovine lymphocytes and rat liver. J. Biol. Chem. 266, 20803-20809

15 Fernandez, C. O., Hoyer, W., Zweckstetter, M., Jares-Erijman, E. A., Subramaniam, V., Griesinger, C. and Jovin, T. M. (2004) NMR of alpha-synuclein-polyamine complexes elucidates the mechanism and kinetics of induced aggregation. Embo J. 23, 2039-2046

16 Mechulam, A., Chernov, K. G., Mucher, E., Hamon, L., Curmi, P. A. and Pastre, D. (2009) Polyamine sharing between tubulin dimers favours microtubule nucleation and elongation via facilitated diffusion. PLoS Comput. Biol. 5, e1000255 
17 Pohjanpelto, P., Virtanen, I. and Holtta, E. (1981) Polyamine starvation causes disappearance of actin filaments and microtubules in polyamine-auxotrophic $\mathrm{CHO}$ cells. Nature. 293, 475-477

18 McCormack, S. A., Ray, R. M., Blanner, P. M. and Johnson, L. R. (1999) Polyamine depletion alters the relationship of F-actin, G-actin, and thymosin beta4 in migrating IEC-6 cells. Am. J. Physiol. 276, C459-468

19 Ray, R. M., McCormack, S. A., Covington, C., Viar, M. J., Zheng, Y. and Johnson, L. R. (2003) The requirement for polyamines for intestinal epithelial cell migration is mediated through Rac1. J. Biol. Chem. 278, 13039-13046

20 Vaidya, R. J., Ray, R. M. and Johnson, L. R. (2005) MEK1 restores migration of polyamine-depleted cells by retention and activation of Rac1 in the cytoplasm. Am. J. Physiol. Cell Physiol. 288, C350-359

21 Tuszynski, J. A., Brown, J. A., Crawford, E. and Carpenter, E. J. (2005) Molecular dynamics simulations of tubulin structure and calculations of electrostatics properties of microtubules. Mathematical and Computer Modelling. 41, 1055-1070

22 Angelini, T. E., Golestanian, R., Coridan, R. H., Butler, J. C., Beraud, A., Krisch, M., Sinn, H., Schweizer, K. S. and Wong, G. C. (2006) Counterions between charged polymers exhibit liquid-like organization and dynamics. Proc. Natl. Acad. Sci. U S A. 103, 7962-7967

23 Tang, J. X. and Janmey, P. A. (1996) The polyelectrolyte nature of F-actin and the mechanism of actin bundle formation. J. Biol. Chem. 271, 8556-8563

24 Priel, A., Tuszynski, J. A. and Woolf, N. J. (2005) Transitions in microtubule Ctermini conformations as a possible dendritic signaling phenomenon. Eur. Biophys J. 35, $40-52$

25 Sackett, D. L., Bhattacharyya, B. and Wolff, J. (1985) Tubulin subunit carboxyl termini determine polymerization efficiency. J. Biol. Chem. 260, 43-45

26 Banan, A., McCormack, S. A. and Johnson, L. R. (1998) Polyamines are required for microtubule formation during gastric mucosal healing. Am. J. Physiol. 274, G879-885

27 Nair, S. K., Verma, A., Thomas, T. J., Chou, T. C., Gallo, M. A., Shirahata, A. and Thomas, T. (2007) Synergistic apoptosis of MCF-7 breast cancer cells by 2methoxyestradiol and bis(ethyl)norspermine. Cancer Lett. 250, 311-322

28 Chernov, K. G., Mechulam, A., Popova, N. V., Pastre, D., Nadezhdina, E. S., Skabkina, O. V., Shanina, N. A., Vasiliev, V. D., Tarrade, A., Melki, J., Joshi, V., Baconnais, S., Toma, F., Ovchinnikov, L. P. and Curmi, P. A. (2008) YB-1 promotes microtubule assembly in vitro through interaction with tubulin and microtubules. BMC Biochem. 9, 23

29 Chernov, K. G., Curmi, P. A., Hamon, L., Mechulam, A., Ovchinnikov, L. P. and Pastre, D. (2008) Atomic force microscopy reveals binding of mRNA to microtubules mediated by two major mRNP proteins YB-1 and PABP. FEBS Lett. 582, 2875-2881

30 Gundersen, G. G., Khawaja, S. and Bulinski, J. C. (1987) Postpolymerization detyrosination of alpha-tubulin: a mechanism for subcellular differentiation of microtubules. J. Cell Biol. 105, 251-264

31 Loukou, Z. and Zotou, A. (2003) Determination of biogenic amines as dansyl derivatives in alcoholic beverages by high-performance liquid chromatography with fluorimetric detection and characterization of the dansylated amines by liquid chromatography-atmospheric pressure chemical ionization mass spectrometry. J. Chromatogr. A. 996, 103-113

32 Beppu, T., Shirahata, A., Takahashi, N., Hosoda, H. and Samejima, K. (1995) Specific depletion of spermidine and spermine in HTC cells treated with inhibitors of aminopropyltransferases. J. Biochem. 117, 339-345 
33 Nitta, T., Igarashi, K. and Yamamoto, N. (2002) Polyamine depletion induces apoptosis through mitochondria-mediated pathway. Exp. Cell. Res. 276, 120-128

34 He, Y., Shimogori, T., Kashiwagi, K., Shirahata, A. and Igarashi, K. (1995) Inhibition of cell growth by combination of alpha-difluoromethylornithine and an inhibitor of spermine synthase. J. Biochem. 117, 824-829

35 Morrison, E. E., Wardleworth, B. N., Askham, J. M., Markham, A. F. and Meredith, D. M. (1998) EB1, a protein which interacts with the APC tumour suppressor, is associated with the microtubule cytoskeleton throughout the cell cycle. Oncogene. 17, 3471-3477

36 Wen, Y., Eng, C. H., Schmoranzer, J., Cabrera-Poch, N., Morris, E. J., Chen, M., Wallar, B. J., Alberts, A. S. and Gundersen, G. G. (2004) EB1 and APC bind to mDia to stabilize microtubules downstream of Rho and promote cell migration. Nat. Cell Biol. 6, 820-830

37 Honore, S., Pagano, A., Gauthier, G., Bourgarel-Rey, V., Verdier-Pinard, P., Civiletti, K., Kruczynski, A. and Braguer, D. (2008) Antiangiogenic vinflunine affects EB1 localization and microtubule targeting to adhesion sites. Mol. Cancer Ther. 7, 20802089

38 Waterman-Storer, C. M., Worthylake, R. A., Liu, B. P., Burridge, K. and Salmon, E. D. (1999) Microtubule growth activates Rac1 to promote lamellipodial protrusion in fibroblasts. Nat. Cell. Biol. 1, 45-50

39 Ligon, L. A. and Holzbaur, E. L. (2007) Microtubules tethered at epithelial cell junctions by dynein facilitate efficient junction assembly. Traffic. 8, 808-819

40 Salmon, W. C., Adams, M. C. and Waterman-Storer, C. M. (2002) Dual-wavelength fluorescent speckle microscopy reveals coupling of microtubule and actin movements in migrating cells. J. Cell Biol. 158, 31-37

41 McCormack, S. A., Viar, M. J. and Johnson, L. R. (1993) Polyamines are necessary for cell migration by a small intestinal crypt cell line. Am. J. Physiol. 264, G367-374

42 Guo, X., Rao, J. N., Liu, L., Zou, T. T., Turner, D. J., Bass, B. L. and Wang, J. Y. (2003) Regulation of adherens junctions and epithelial paracellular permeability: a novel function for polyamines. Am. J. Physiol. Cell Physiol. 285, C1174-1187

43 Giepmans, B. N., Verlaan, I., Hengeveld, T., Janssen, H., Calafat, J., Falk, M. M. and Moolenaar, W. H. (2001) Gap junction protein connexin-43 interacts directly with microtubules. Curr. Biol. 11, 1364-1368

44 Shaw, R. M., Fay, A. J., Puthenveedu, M. A., von Zastrow, M., Jan, Y. N. and Jan, L. Y. (2007) Microtubule plus-end-tracking proteins target gap junctions directly from the cell interior to adherens junctions. Cell. 128, 547-560

45 Ignatenko, N. A., Zhang, H., Watts, G. S., Skovan, B. A., Stringer, D. E. and Gerner, E. W. (2004) The chemopreventive agent alpha-difluoromethylornithine blocks Kiras-dependent tumor formation and specific gene expression in Caco-2 cells. Mol. Carcinog. 39, 221-233

46 Shore, L., Mclean, P., Gilmour, S. K., Hodgins, M. B. and Finbow, M. E. (2001) Polyamines regulate gap junction communication in connexin 43-expressing cells. Biochem. J. 357, 489-495

47 Holmfeldt, P., Brattsand, G. and Gullberg, M. (2002) MAP4 counteracts microtubule catastrophe promotion but not tubulin-sequestering activity in intact cells. Curr. Biol. 12, 1034-1039

48 Nguyen, H. L., Gruber, D. and Bulinski, J. C. (1999) Microtubule-associated protein 4 (MAP4) regulates assembly, protomer-polymer partitioning and synthesis of tubulin in cultured cells. J. Cell. Sci. 112 ( Pt 12), 1813-1824 
49 Permana, S., Hisanaga, S., Nagatomo, Y., Iida, J., Hotani, H. and Itoh, T. J. (2005) Truncation of the projection domain of MAP4 (microtubule-associated protein 4) leads to attenuation of microtubule dynamic instability. Cell. Struct. Funct. 29, 147-157

50 Illenberger, S., Drewes, G., Trinczek, B., Biernat, J., Meyer, H. E., Olmsted, J. B., Mandelkow, E. M. and Mandelkow, E. (1996) Phosphorylation of microtubuleassociated proteins MAP2 and MAP4 by the protein kinase p110mark. Phosphorylation sites and regulation of microtubule dynamics. J. Biol. Chem. 271, 10834-10843

51 Rogers, G. C., Rusan, N. M., Peifer, M. and Rogers, S. L. (2008) A multicomponent assembly pathway contributes to the formation of acentrosomal microtubule arrays in interphase Drosophila cells. Mol. Biol. Cell. 19, 3163-3178

52 Fumoto, K., Hoogenraad, C. C. and Kikuchi, A. (2006) GSK-3beta-regulated interaction of BICD with dynein is involved in microtubule anchorage at centrosome. Embo J. 25, 5670-5682

53 Osborn, M. and Weber, K. (1976) Cytoplasmic microtubules in tissue culture cells appear to grow from an organizing structure towards the plasma membrane. Proc. Natl. Acad. Sci. U S A. 73, 867-871

54 Sousa, A., Reis, R., Sampaio, P. and Sunkel, C. E. (2007) The Drosophila CLASP homologue, Mast/Orbit regulates the dynamic behaviour of interphase microtubules by promoting the pause state. Cell. Motil. Cytoskeleton. 64, 605-620

55 Efimov, A., Kharitonov, A., Efimova, N., Loncarek, J., Miller, P. M., Andreyeva, N., Gleeson, P., Galjart, N., Maia, A. R., McLeod, I. X., Yates, J. R., 3rd, Maiato, H., Khodjakov, A., Akhmanova, A. and Kaverina, I. (2007) Asymmetric CLASPdependent nucleation of noncentrosomal microtubules at the trans-Golgi network. Dev. Cell. 12, 917-930 


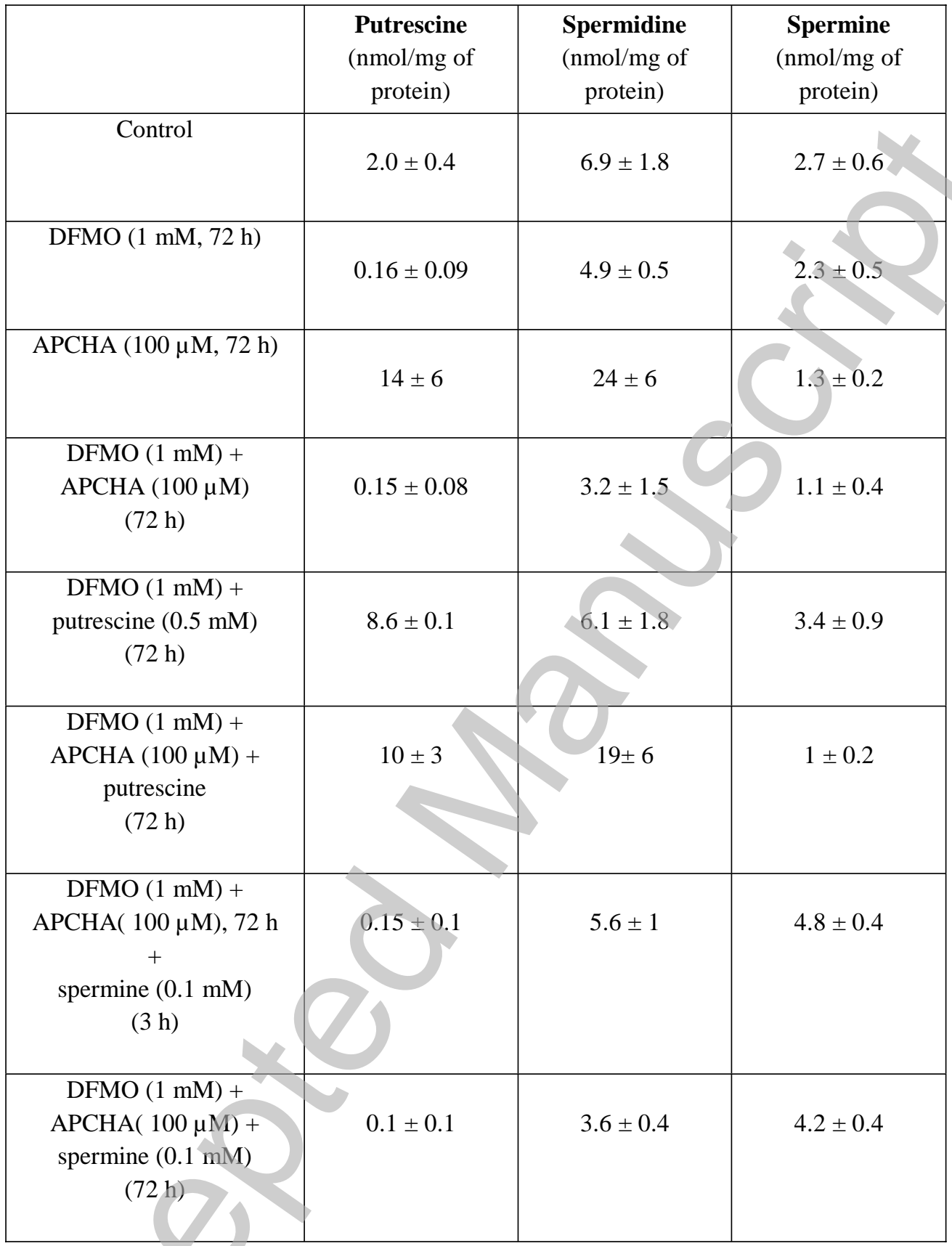

\section{Table 1}




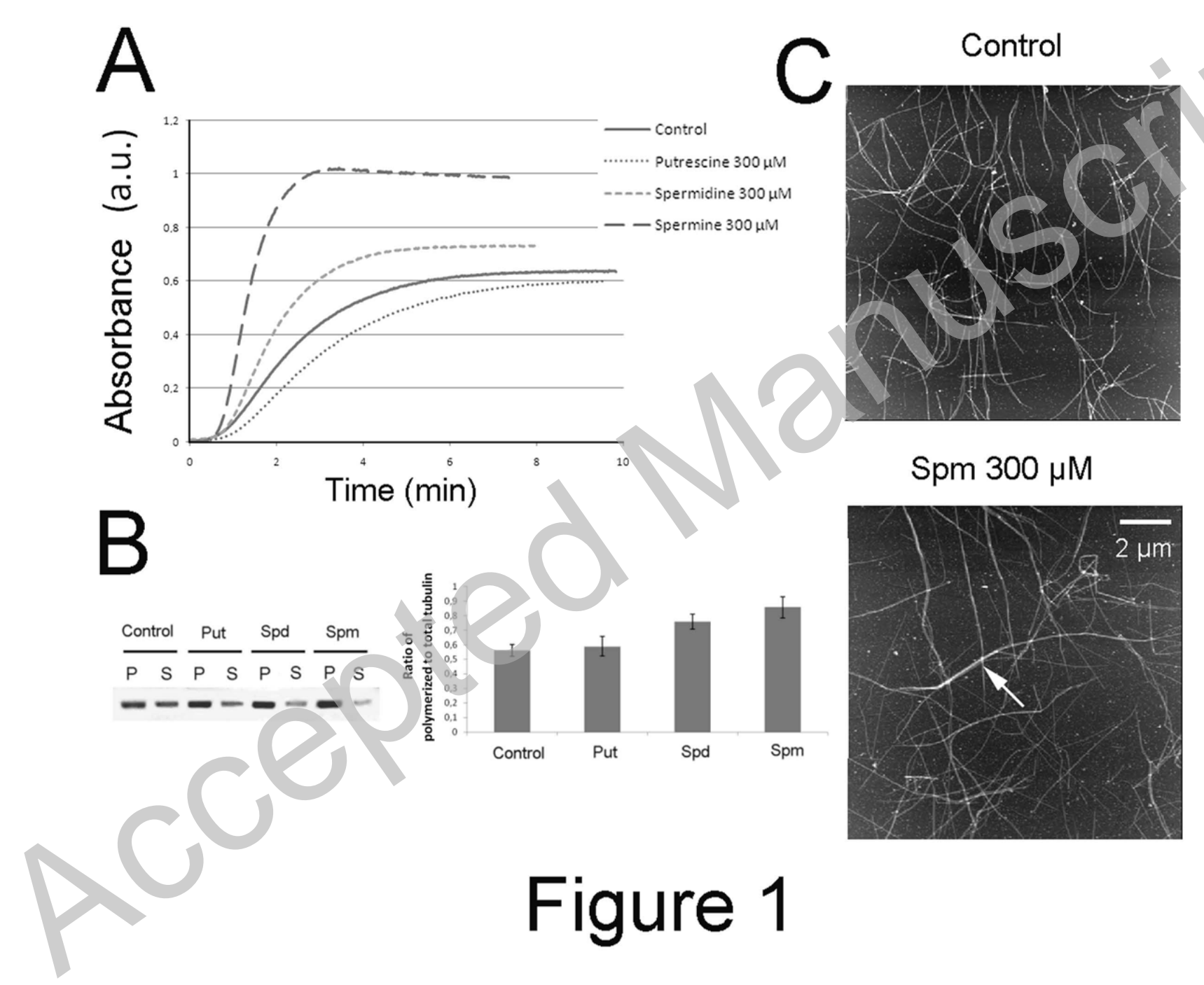


Biochemical Journal Immediate Publication. Published on 04 Jun 2010 as manuscript BJ20091811

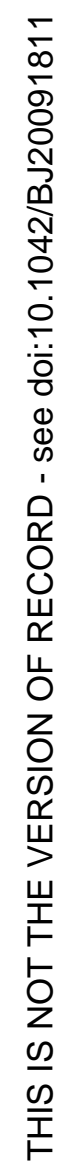
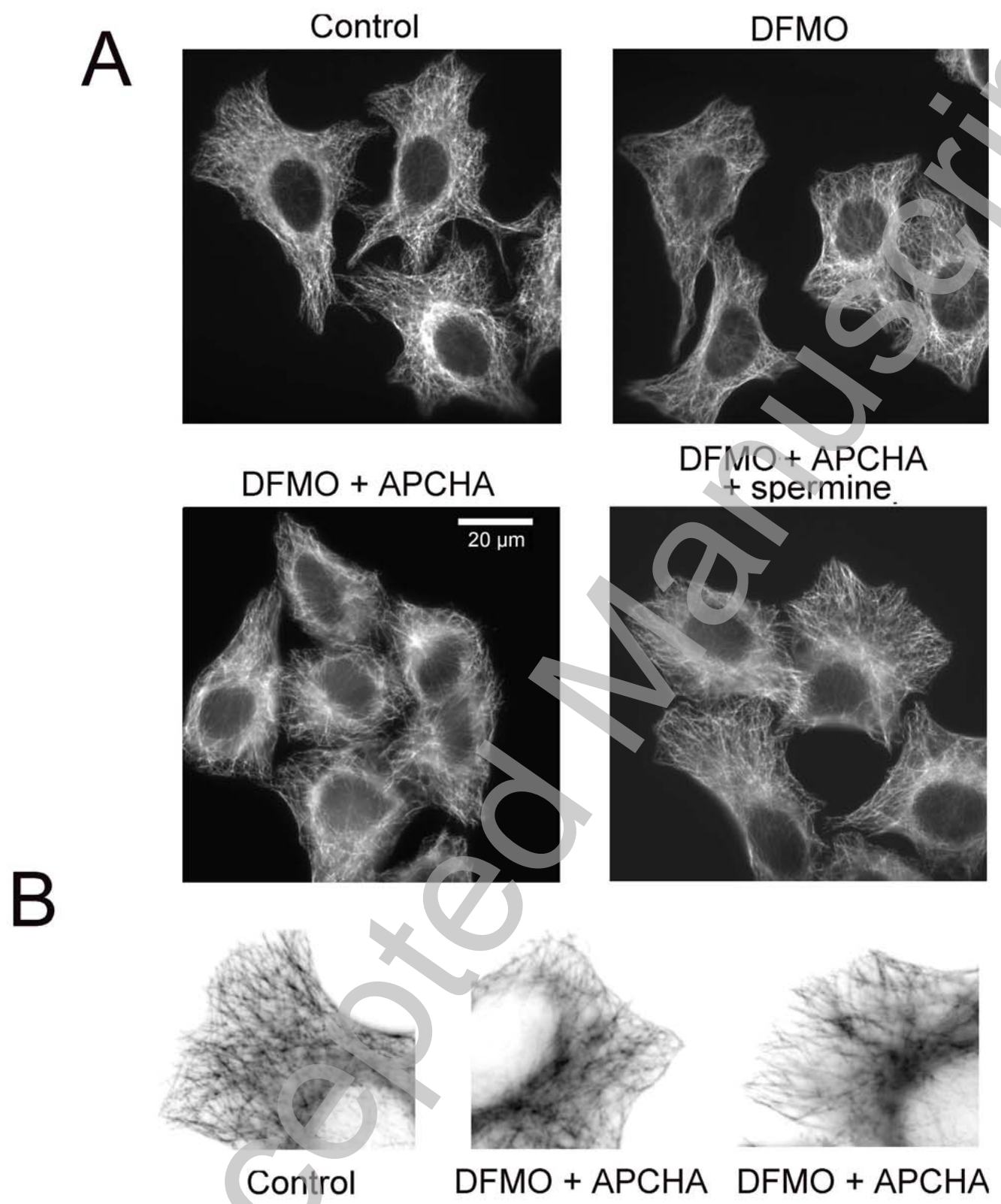

Control

$\mathrm{DFMO}+\mathrm{APCHA}$

+ spermine

\section{Figure 2}


B) Biochemical Journal Immediate Publication. Published on 04 Jun 2010 as manuscript BJ20091811

A

Control

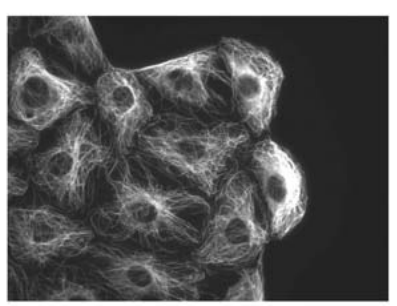

DFMO + APCHA (72 h)

DFMO + APCHA (72 h)

Addition of spermine $(3 \mathrm{~h})$

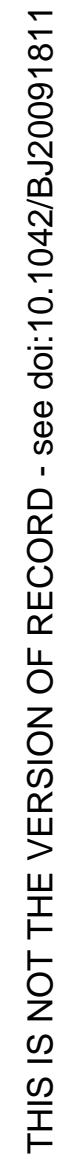

B
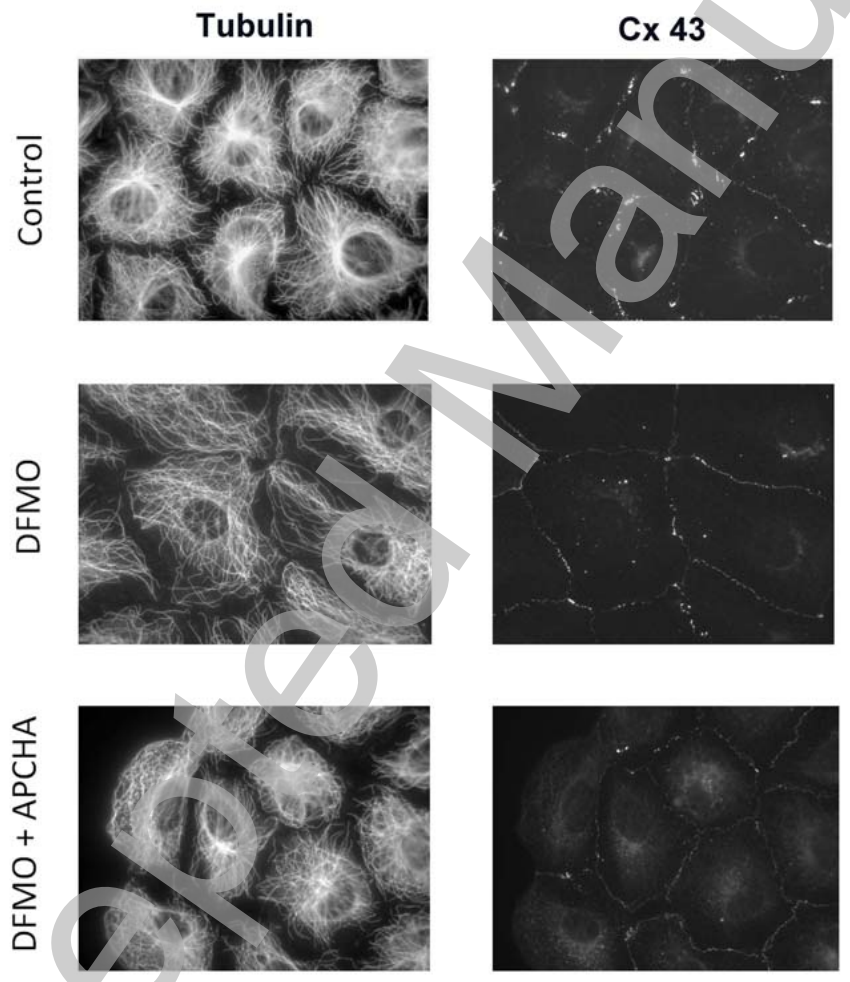

Figure 4

Licenced copy. Copying is not permitted, except with prior permission and as allowed by law. (C) 2010 The Authors Journal compilation (c) 2010 Portland Press Limited 


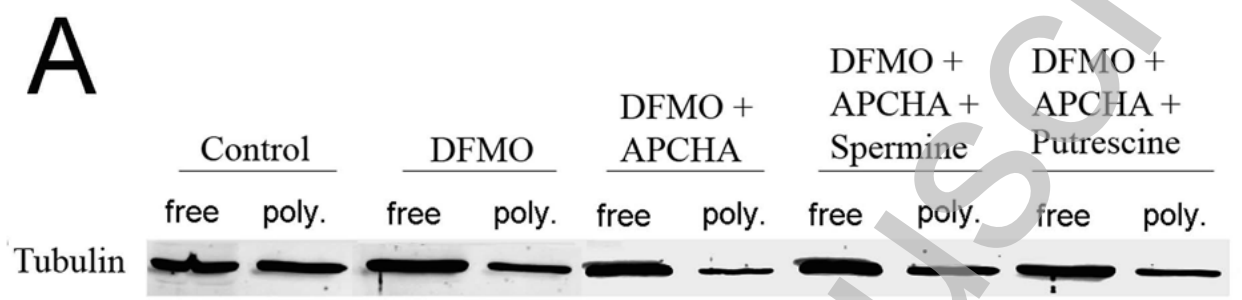

\section{Figure 5}


B) Biochemical Journal Immediate Publication. Published on 04 Jun 2010 as manuscript BJ20091811
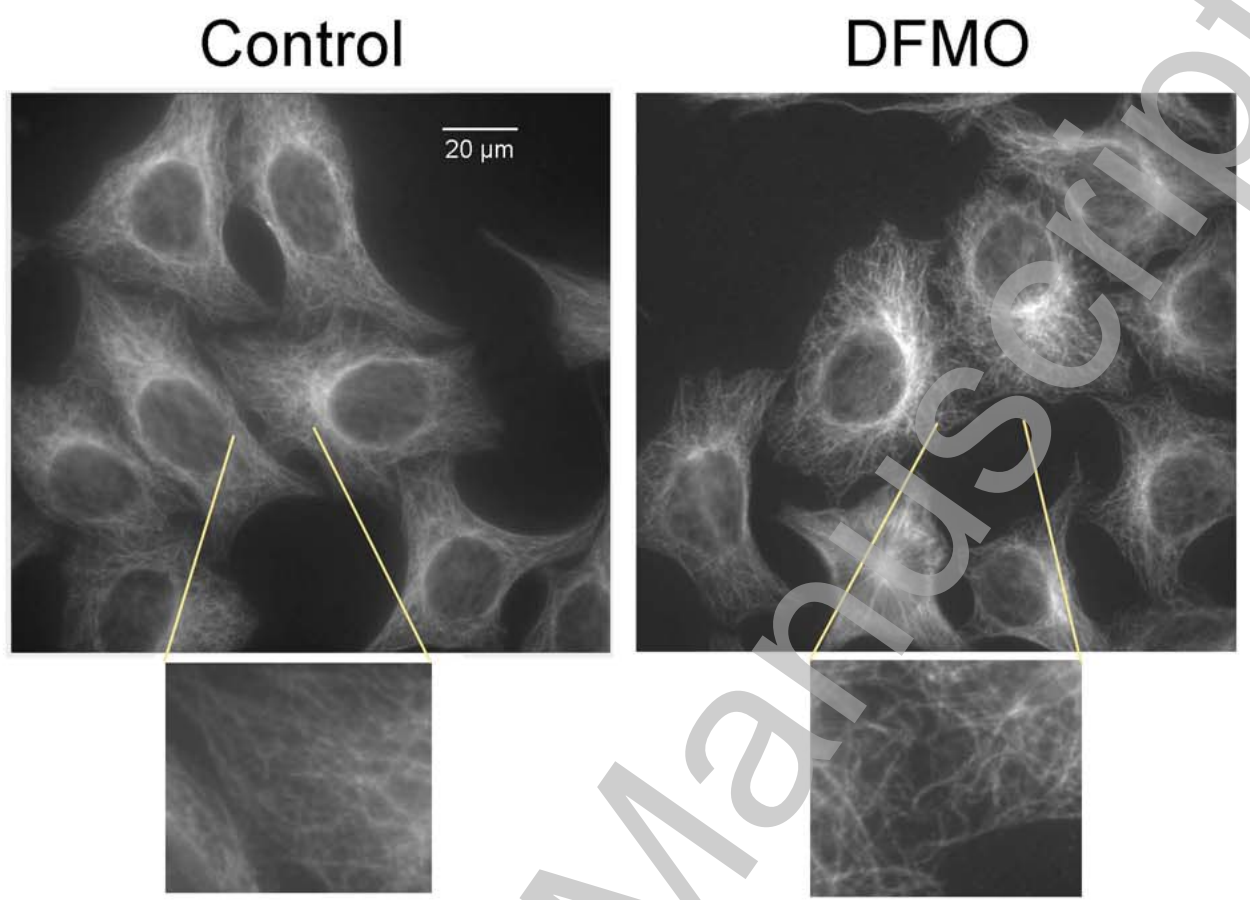

$\mathrm{DFMO}+\mathrm{APCHA}$

\section{$\mathrm{DFMO}+\mathrm{APCHA}$} +spermine
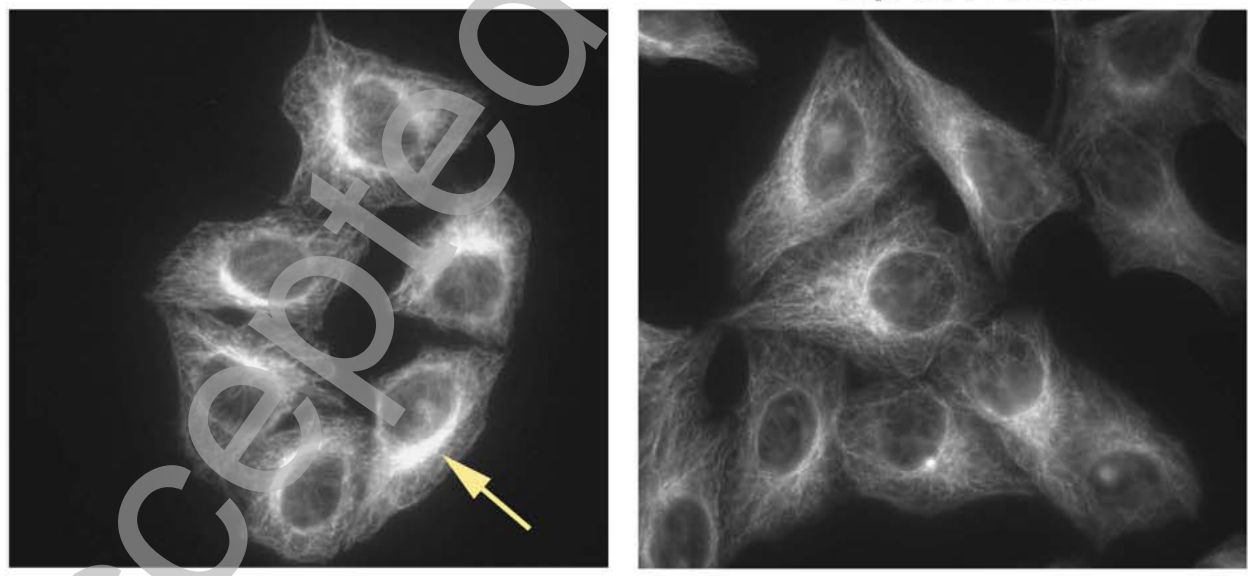

\section{Figure 6}




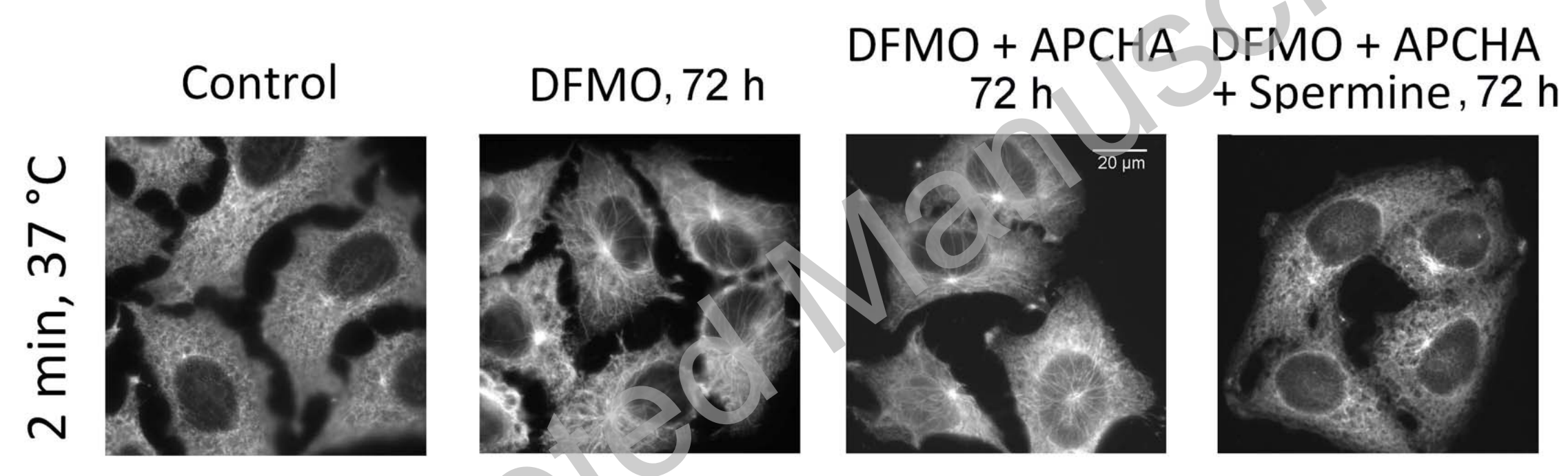

\section{Figure 7}

